\title{
Rechtsgeschichte
}

\section{Horst Dreier}

\section{Säkularisierung des Staates am Beispiel der Religionsfreiheit}




\section{Säkularisierung des Staates am Beispiel der Religionsfreiheit}

\section{Begrifflichkeit und Abgrenzungen}

Säkularisierung ist ein großes, ja epochales Thema, dem Michael Stolleis eingehende Überlegungen gewidmet hat. ${ }^{{ }^{I}}$ Dabei ist die thematische Erweiterung ebenso wie die disziplinäre Verzweigung der Säkularisierungsdebatte in den letzten Jahrzehnten derartig fortgeschritten, ${ }^{2}$ dass man zur Vermeidung von Missverständnissen mindestens zwischen den folgenden drei Aspekten resp. Prozessen der Säkularisierung unterscheiden sollte.

Mit Säkularisierung kann erstens gemeint sein, dass es in einer Gesellschaft zu einem »decline of religious beliefs « kommt, also zu einem Rückgang gelebter religiöser Praxis, dem Nachlassen oder gar dem Verfall des Glaubens und seines Bekenntnisses, einem wachsenden Anteil religiös ungebundener Personen an der Bevölkerung. Säkularisierung bezeichnet hier den Umstand einer mehr oder minder umfassenden Verringerung der religiösen Bindung eines politischen Gemeinwesens und seiner Mitglieder. Diese erste Dimension lässt sich prinzipiell mit Mitteln der empirischen Sozialforschung »messen «. Freilich ist hier immer zu bedenken, dass Entkirchlichung im Sinne einer Abnahme formeller Kirchenmitgliedschaft, so wichtig diese als Indikator ist, nicht zwingend Religionsschwund bedeutet.

Zweitens kann Säkularisierung als eine fundamentale geistesgeschichtliche Interpretationskategorie fungieren, die die Loslösung verschiedener Sphären und gesellschaftlicher Bereiche (Politik, Kunst, Wissenschaft) aus der Dominanz religiöser Bindung und Deutung beschreibt. Als Exempel mag die wirkmächtige Wendung Max Webers von der »Entzauberung der Welt « gelten. Säkularisierung meint insofern eine Art Substanzwandel christlicher Vorstellungen, eine Transformation des originär Religiösen in weltliche Bereiche, eine Umbesetzung zentraler Begriffe. Ebenso berühmt wie letztlich haltlos ist das Diktum Carl Schmitts, wonach alle prägnanten staatsrechtlichen Begriffe säkularisierte theologische Begriffe seien. Konkreter hat man eine solche Transformation bis in die religiöse Prägung der Sprache in der Dichtung nachgewiesen

I M. Stolleis, »Konfessionalisierung " oder "Säkularisierung « bei der Entstehung des frühmodernen Staates, in: Ius Commune XX (I993) I-23.

2 Instruktiv M. Pohlig, U. LotzHeumann, V. Isaiasz, R. SchilLING, H. BOCK, ST. EHRENPREIS, Säkularisierungen in der Frühen Neuzeit. Methodische Probleme und empirische Fallstudien, Berlin 2008, insb. die Rekapitulation der verschiedenen Diskussionsstränge und Theorieangebote 2I-I09. 
(»literarische Säkularisierung «). Aber auch der Wandel der Legitimierung politischer Herrschaft von religiöser hin zu innerweltlicher Begründung kann als Beispiel dienen. Dieser Prozess ist Gegenstand einer Vielzahl von kulturwissenschaftlichen und ideengeschichtlichen Disziplinen.

Drittens schließlich kann Säkularisierung einen epochalen Ausdifferenzierungsprozess meinen, in dem es u. a. zur Trennung von Staat und Kirche kommt, also zur sukzessiven religiösen Neutralisierung des staatlichen Sektors und seiner Institutionen sowie zu einer entsprechenden Privatisierung (und zumeist auch Pluralisierung) der Ausübung des Glaubens. Der Staat wird zu einer säkularen Größe. Das heißt insbesondere, dass der Staat die Entscheidung über letzte Wahrheiten, wie sie die Religion verkündet, dem Einzelnen überlässt. Der säkulare Staat der Moderne ist nicht Wahrheits- oder Tugendstaat, sondern Freiheits- und Friedensordnung. Deshalb gilt das Gebot der Nicht-Identifikation: Er darf sich mit keiner Religion und mit keiner Weltanschauung identifizieren. Dieser Prozess ist vornehmlich Gegenstand des Staatsrechts, der Verfassungsgeschichte und der politischen Wissenschaften.

Es liegt auf der Hand, dass zwischen den drei Phänomenen kein funktionaler Wirkungszusammenhang besteht. Insbesondere steht der erste Aspekt (decline of religious beliefs) mit dem dritten (religiöse Neutralität des Staates) in keiner zwingenden Verbindung. Die rein innerweltliche Legitimation des Staates kann Breite und Intensität des religiösen Glaubens durchaus stärken; und umgekehrt kann der zunehmende Verlust an religiöser Bindung im Sinne von »decline of religious beliefs « mit einer staatlichen Verfassung einhergehen, in der eine Staatskirche besteht oder sonst die Trennung von Staat und Kirche noch nicht sehr weit fortgeschritten ist. Das uns naheliegende Beispiel der ehemaligen DDR zeigt aber eben auch, dass forcierte Kirchen- und Religionsfeindlichkeit eines Staates durchaus zu einem signifikanten Nachlassen religiöser Bindungen der Gesamtbevölkerung führen kann. Totalitäre Ordnungen haben hier und andernorts ihre Wirkung selten verfehlt.

In diesem kleinen und notgedrungen sehr holzschnittartigen Beitrag geht es allein um den dritten Aspekt, also die Säkularisierung als Vorgang zunehmender Trennung von Staat und Kirche mit parallel dazu verlaufender Freisetzung der Glaubensfreiheit. Ganz ausgeblendet bleibt die »Säkularisation « im engeren Sinne eines 
scharf abgegrenzten juristischen Terminus, mit dem die Aufhebung geistlicher Fürstentümer und die Einziehung des Kirchenvermögens durch die weltliche Obrigkeit bezeichnet werden. Das bedeutendste Beispiel für eine solche Enteignung und Übertragung bildet der Reichsdeputationshauptschluss von I 803 , der das Ende des Heiligen Römischen Reiches Deutscher Nation besiegelte. ${ }^{3}$ Schon aus Gründen begrifflicher Klarheit sollte man in dieser Weise zwischen Säkularisierung und Säkularisation unterscheiden. ${ }^{4}$

Säkularisierung im vornehmlich staats- und verfassungsrechtlichen Sinne trägt ein Doppelgesicht. Religiöse Neutralität des Staates bildet sozusagen die andere Seite der Medaille der Glaubens- und Religionsfreiheit. Glaubensfreiheit und religiös neutraler Staat bedingen sich wechselseitig. Erst der religiös neutrale Staat kann die Religions- und Glaubensfreiheit völlig freigeben; erst durch die Freigabe der Religions- und Glaubensfreiheit wird er zum neutralen Staat. Historisch gesehen war es bis dahin freilich ein weiter, langer und schwieriger Weg. Er zeigt zugleich, welch wichtige Rolle die Glaubensfreiheit für die Entwicklung der modernen Menschenrechte gespielt hat, auch wenn man entgegen der These von Georg Jellinek die Religionsfreiheit wohl kaum als eine Art von Ur-Grundrecht wird ansehen können. Die wesentlichen Etappen der Durchsetzung der Religionsfreiheit sollen im Folgenden am Leitfaden der rechtsnormativen Entwicklung betrachtet werden, und zwar unter Beschränkung auf Deutschland, ohne sie insofern - das sei zur Vermeidung von Missverständnissen vorausgeschickt - als normatives Vorbild oder verallgemeinerbares Modell begreifen zu wollen. Und ebensowenig soll behauptet werden, dass die hier nachzuzeichnenden Entwicklungsschritte gleichsam historisch notwendige Stufen sind. Wie alle historischen Prozesse ist auch dieser in seiner Art einmalig.

\section{Historische Entwicklungsstufen}

\section{Investiturstreit}

In einem höchst einflussreichen Beitrag hat Ernst-Wolfgang Böckenförde diesen Prozess mit dem Investiturstreit im elften und zwölften Jahrhundert beginnen lassen. ${ }^{5}$ Das mag überraschen. Doch arbeitet Böckenförde überzeugend heraus, dass mit dem streitbeendenden Wormser Konkordat aus dem Jahre I I 22 eine

land, Bd. I: Reichspublizistik und Policeywissenschaft I600-I 800 , München I988, 330 f.; siehe auch Der Reichsdeputationshauptschluss von $\mathrm{I} 8 \mathrm{O}_{3}$, hg. von $\mathrm{U}$. HuFELD, Köln 2003.

4 So kennt das "Staatslexikon der Görres-Gesellschaft« zwei getrennte Artikel (7. Aufl., Bd. IV, I988, 990-993 und 993-998), während in der Enzyklopädie »Religion in Geschichte und Ge- genwart « nur ein Lemma »Säkularisierung / Säkularisation « erscheint (4. Aufl., Bd. 7, Tübingen 2004, 774-788).

5 E.-W. BöCKENFÖRDE, Die Entstehung des Staates als Vorgang der Säkularisation (1967), in: DERS., Staat, Gesellschaft, Freiheit. Studien zur Staatstheorie und zum Verfassungsrecht, Frankfurt a. M. I976, 42-64 (44 ff.). 
Trennung zwischen staatlicher Gewalt und kirchlichen Institutionen festgeschrieben wurde. ${ }^{6}$ Kirchliche und staatliche Ämter sowie die Kompetenzen auf weltlichem und geistlichem Feld wurden stärker als zuvor geschieden, ein Cäsaropapismus gerade nicht realisiert, Theorie und Praxis einer lange Zeit dominanten Reichskirche faktisch negiert. Bei aller fortdauernden Prägung der weltlichen Seite durch die christliche Religion, genauer: durch die konfessionell noch ungeteilte römisch-katholische Kirche, wurde doch eine Ausdifferenzierung zweier Sphären bestätigt und bekräftigt, die denknotwendige Voraussetzung für den weiteren Entwicklungsprozess war. Um Religionsfreiheit geht es im Investiturstreit natürlich noch nicht, »da nur eine Religion, institutionalisiert in einer Kirche, existiert und die Negation von Religion grundsätzlich nicht vorgesehen ist «. ${ }^{7}$ Aber die systematische Scheidung von geistlicher und weltlicher Gewalt war doch folgenschwer vorangetrieben und somit ein erster Schritt zur »Säkularisierung weltlicher Herrschaft $\ll^{8}$ getan.

\section{Reformation und Augsburger Religionsfrieden I 555}

"Die Reformation hat Freiheit des Glaubens weder gebracht noch auch nur erstrebt. Was sie brachte, ist nicht Glaubensfreiheit, sondern Glaubenszweiheit. «" Die Konkurrenz zwischen zwei (und bald drei) verschiedenen Konfessionen (katholisch, evangelisch, reformiert) bewirkt eine umfassende und tiefgreifende »Konfessionalisierung « des staatlichen und gesellschaftlichen Lebens mit hohem Uniformitätsdruck in den jeweiligen Territorien. ${ }^{{ }^{\circ}}$ Gleichwohl kommt es aber im Heiligen Römischen Reich Deutscher Nation in Gestalt des Augsburger Religionsfriedens aus dem Jahre I 555 zu allerersten Ansätzen von religiösen Freiheitsgarantien. Dieses Staatsgrundgesetz anerkannte neben dem katholischen Glaubensbekenntnis auch das evangelische. Damit war auf dem Boden des Reiches (nicht: der Territorien) Glaubenszweiheit garantiert, eine frühe und rudimentäre Form des Pluralismus also. »Im Reich galten rechtliche Neutralität, Parität, bikonfessionelle Offenheit und Relativierung des beidseitigen Konfessionsanspruchs, im Territorium aber prinzipielle Konfessionseinheit, Imparität und Absolutheitsgeltung der herrschenden Landeskonfession. " ${ }^{\text {II }}$ Allerdings bedeutete diese Glaubenszweiheit noch keine individuelle Glaubensfreiheit. Genauer gesagt: Diese Glaubensfreiheit stand nur

6 Siehe auch H. J. Berman, Recht und Revolution. Die Bildung der westlichen Rechtstradition, Frankfurt a. M. I99I, I6I ff. mit Betonung der Machtsteigerung des Papsttums (I67 f.).

7 Chr. Waldhoff, Die Zukunft des Staatskirchenrechts, in: Die Verfassungsordnung für Religion und Kirche in Anfechtung und Bewährung, Münster 2008, $55^{-}$ IOI (60).
8 Chr. Link, Kirchliche Rechtsgeschichte, München 2009, $\mathbb{} 5$ Rn. I7 (S. 35).

9 So G. Anschütz, Die Religionsfreiheit, in: Handbuch des Deutschen Staatsrechts, hg. von G. Anschütz, R. Thома Bd. 2, Tübingen 1932, $\mathbb{S}$ 106, 675-689 (676).

Io Siehe nur Stolleis, Geschichte I (Fn. 3) I 26 ff. (»Konfessionsstreit und Staatsbildung «). Näher zur
Konfessionalisierungsdebatte und ihrem Ertrag für Verfassungsgeschichte und Staatstheorie H. Dreier, Kanonistik und Konfessionalisierung - Marksteine auf dem Weg zum Staat, in: Artibus ingenuis, hg. von G. SIEBECK, Tübingen 200I, I33-I69 (I48 ff.), auch in: JZ 2002, I-I3 (6ff.).

I I M. HeCKel, Vom Religionskonflikt zur Ausgleichsordnung, München 2007, I I. 
I2 A. Freiherr von CAmpenhauSEN, Religionsfreiheit, in: Handbuch des Staatsrechts der Bundesrepublik Deutschland, hg. von J. Isensee, P. Kirchhof, 3. Aufl.,

den Territorialherren zu, für die sie in Gestalt des ius reformandi zugleich und in allererster Linie ein Herrschaftsrecht war: Religionshoheit. Denn die freie Wahl zwischen dem römisch-katholischen und dem Augsburger Bekenntnis garantierte ihnen die zwangsweise Bestimmung der Religionsverhältnisse in ihrem Territorium (sog. Religionsbann). Hier gibt es also nicht Glaubensfreiheit gegen die Obrigkeit, sondern Glaubensfreiheit der Obrigkeit. Ein konfessionelles Wahlrecht steht den Landesherren zu, nicht den Untertanen. Das ist der Kern der Formel »cuius regio, eius religio«. Und doch brachte der Augsburger Religionsfrieden gleichsam reflexhaft den Ansatz eines auch den Untertanen gewährten Freiheitsrechts, das ius emigrandi ( $\mathbb{2} 24)$. Diese Auswanderungsfreiheit wurde den konfessionsverschiedenen Landesbewohnern als Individualrecht garantiert. Sie gründete letztlich auf einer abweichenden Konfessionswahl und transformierte den daraus resultierenden Konflikt in eine Art von religiöser Freizügigkeit. ${ }^{\text {I2 }}$ Erreicht war damit nur, aber immerhin, »beschränkte Religionsfreiheit gegen obrigkeitliche Zwangsbekehrung «. ${ }^{{ }^{13}}$

\section{Westfälischer Frieden I 648}

Der Westfälische Frieden von $1648^{14}$ vertieft und erweitert diese Ansätze in mehrfacher Hinsicht. Zum einen wird, um sich an die klassische Formulierung von Anschütz anzulehnen, die Glaubenszweiheit zur "Glaubensdreiheit ${ }^{\mathrm{I} 5}$ erweitert, indem man neben dem katholischen und dem evangelischen Bekenntnis auch das reformierte zuließ (Art. VII IPO); andere »Sekten « (etwa Herrnhuter oder Baptisten) blieben allerdings weiterhin verboten. Zum anderen wurde durch die Fixierung eines Normaljahres (I624) das ius reformandi des Territorialherrn eingeschränkt, ja partiell aufgehoben. Denn freie Religionsausübung (»exercitium religionis«) wurde für die Zukunft in dem Umfang gewährleistet, in dem die Bekenntnisse nacheinander oder gleichzeitig öffentlich hatten ausgeübt werden dürfen. Der Landesherr musste nunmehr im Unterschied zu I 555 dulden, dass zu seinen Untertanen konfessionsverschiedene Personen gehörten. Doch unabhängig davon gab es weiterhin in jedem Territorium jeweils eine privilegierte Staatskirche. Damit war die konfessionelle Landkarte Deutschlands für Jahrhunderte fixiert. Neben das exercitium publicum dieser herrschenden Landesreligion (mit Kirchtürmen und Glockengeläut,

Bd. 7, Heidelberg 2009, $\mathbb{1} 57$ Rn. I 5: "erster und bescheidener Anfang der Anerkennung des Grundrechts der Religionsfreiheit, zunächst im Gewande religiöser Freizügigkeit «.

I 3 Heckel, Religionskonflikt (Fn. I I) IO.

I4 Stolleis, Geschichte I (Fn. 3) $225 \mathrm{ff}$. Weitere hochkomprimierte Darstellungen bei K. ScHlaich, Art. Westfälischer Frieden, in:
Evangelisches Staatslexikon, 3. Aufl., Bd. II, I987, 3970-3974; M. Heckel, Der Westfälische Friede als Instrument internationaler Friedenssicherung und religiös-weltanschaulicher Koexistenzordnung, in: JuS I988, 336$34 \mathrm{I}$.

I 5 M. Morlok, in: GrundgesetzKommentar, hg. von H. DreIER, Bd. I, 2. Aufl. Tübingen 2004, Art. 4 Rn. 4 . 
Staatsakten und Feiertagen) trat das exercitium privatum der anderen Konfessionen mit stark eingeschränktem Wirkungsfeld. Und schließlich wurde mit der Möglichkeit der Hausandacht (Art. V $\mathbb{3 4}$ IPO) auch für jene, die keinen derartigen Anspruch wegen des Normaljahres geltend machen konnten, neben dem fortbestehenden ius emigrandi eine Möglichkeit religiöser Betätigung geschaffen. ${ }^{\mathbf{I}}$ Erstmals taucht hier die Formulierung von der "conscientia libera ", der Gewissensfreiheit, auf. Das religiöse Handeln gemäß dem Gewissen wurde freilich nur »gehörig « toleriert und durfte nicht öffentlich praktiziert werden. Man fürchtete ansonsten eine Gefährdung der öffentlichen Sicherheit und Ordnung. In gewisser Parallele hierzu steht, wenn in verschiedenen nordamerikanischen Colonial Charters die »freedom of conscience « unter den Vorbehalt des »live quietly under the Civil Government « (Charter of Delaware, I 7OI) oder des » not giving offence or scandal to the government " (Charter of Georgia, I732) gestellt wurde. ${ }^{17}$ Insgesamt waren 1648 individuelle Berechtigungen nur eine Art Nebenprodukt korporativer Rechte der Reichsstände als Religionsparteien. Am prinzipiell christlichen Charakter des Reiches wie der Territorien bestand kein Zweifel.

\section{Preußisches ALR I794}

Interessanterweise war es Preußen, das im I8. Jahrhundert über die Rechtsgarantien des Westfälischen Friedens deutlich hinausging und zunehmend eine staatliche Gleichbehandlung der Konfessionen praktizierte. Nicht von ungefähr sah Anschütz im altpreußischen Staatskirchenrecht die »Wurzeln der deutschen Religionsfreiheit « liegen. ${ }^{\text {I8 }}$ Hatte der Westfälische Frieden eine Duldung der Sekten noch ausdrücklich ausgeschlossen (Art. VII $\int 2$ S. 4 IPO), praktizierte man in Preußen insofern Toleranz, auch wenn die öffentliche Religionsausübung mit »Turm und Glocken « (exercitium religionis publicum) nur den drei reichsrechtlich anerkannten christlichen Konfessionen (Katholiken, Lutheraner, Reformierte) zustand. Diese drei aber wurden vom Staat, der sich mit keiner von ihnen identifizierte, gleichbehandelt. Bemerkenswert modern, weil Individualrechte gewährend, wirken zudem etwa folgende Bestimmungen des Preußischen Allgemeinen Landrechts von 1794 (PrALR II II): » $\mathbb{I}$ I. Die Begriffe der Einwohner des Staats von Gott und göttlichen Dingen, der Glaube, und der innere

I6 Details bei M. Heckel, Zu den Anfängen der Religionsfreiheit im Konfessionellen Zeitalter (2003), in: DERS., Gesammelte Schriften, Bd. V, Tübingen 2004, 8I-I34 ( 92 ff.): "Das abgestufte Religionsexerzitium nach der Normaljahrsregelung des IPO $\ll$.

I7 Hinweis darauf bei Morlok

(Fn. I 5), Art. 4 Rn. 5 mit Fn. I4.
I8 ANSCHÜTZ, Religionsfreiheit (Fn. 9) 677; ihm folgend CAMPENHAUSEN (Fn. I2), \ I 57 Rn. 25. 
Gottesdienst, können kein Gegenstand von Zwangsgesetzen seyn. $\mathbb{S}$ 2. Jedem Einwohner im Staate muß eine vollkommene Glaubensund Gewissensfreyheit gestattet werden. [...] $\mathbb{S}$ 3. Niemand ist schuldig, über seine Privatmeinungen in Religionssachen Vorschriften vom Staate anzunehmen. $\mathbb{4}$ 4. Jedem Bürger des Staats, welchen die Gesetze fähig erkennen, für sich selbst zu urtheilen, soll die Wahl der Religionspartey, zu welcher er sich halten will, frey stehn. «Bei der eigenständigen Konzeption der Religionsfreiheit als einem subjektiven Recht des Individuums spielt das Preußische Landrecht also in der Tat eine »Vorreiterrolle «. ${ }^{\text {I9 }}$ Freilich unterwarf der Staat die in » öffentlich aufgenommene « und "geduldete « unterteilten Kirchengesellschaften ( 13 II I I ff. PrALR) seiner Aufsicht und Leitung. Trennung von Staat und Kirche war weder realisiert noch auch nur intendiert: "Die staatliche Kirchenhoheit wurde im preußischen Staate des I8. und auch noch des frühen I9. Jahrhunderts ebenso scharf und sterritorialistisch gehandhabt wie anderwärts und wie es dem Geist des Zeitalters entsprach. « ${ }^{20}$ Das erklärte die Kirchen »zu gleichzeitig privilegierten und bevormundeten Anstalten des Staates «. ${ }^{2 \text { I }}$ Auch gab es den Kirchenaustritt nur als Kirchenübertritt (4 I II I I PrALR: »Der Übergang von einer Religionspartey zu einer anderen geschieht in der Regel durch ausdrückliche Erklärung. «). Völlige Religionslosigkeit war nicht vorgesehen, ${ }^{22}$ genausowenig die freie (also von staatlicher Genehmigung unabhängige) Vereinigung zu Religionsgesellschaften ( I II I I PrALR). Dennoch ging das Preußische Allgemeine Landrecht einen entscheidenden Schritt in Richtung allgemeiner Religionsfreiheit kraft Gleichstellung verschiedener (nicht: aller) christlichen Glaubensrichtungen.

\section{Paulskirchenverfassung $1848 / 49$}

Bei den Regelungen des Westfälischen Friedens und auch in der weitergehenden Liberalisierung und Pluralisierung des Glaubens in Preußen handelte es sich noch nicht um volle Religionsfreiheit im Sinne eines Grund- oder Menschenrechtes einer jeden Person. Vollumfänglich begegnet uns eine solche Regelung erst in der in jeder Hinsicht hochmodernen Paulskirchenverfassung von I 848/ 49, die auch insofern einen qualitativen Sprung markiert. Dort heißt es in $\mathbb{S}$ I44: "Jeder Deutsche hat volle Glaubens- und Gewissensfreiheit. Niemand ist verpflichtet, seine religiöse Ueberzeu-

I9 ST. Korioth, Vom institutionellen Staatskirchenrecht zum grundrechtlichen Religionsverfassungsrecht? Chancen und Gefahren eines Bedeutungswandels des Art. I40 GG, in: Der Staat des Grundgesetzes - Kontinuität und Wandel. Festschrift für Peter Badura zum siebzigsten Geburtstag, Tübingen 2004, 727-747 (735). 20 ANschüTZ, Religionsfreiheit (Fn. 9) 678.
2I Korioth, Staatskirchenrecht (Fn. I9) 734.

22 v. Campenhausen (Fn. I 2), $\$$ I 57 Rn. 26. 
gung zu offenbaren. « $\mathbb{\text { I } 4 5}$ normiert: »Jeder Deutsche ist unbeschränkt in der gemeinsamen häuslichen und öffentlichen Uebung seiner Religion. « Schließlich garantiert $\$$ I 47 III mit der religiösen Vereinigungsfreiheit etwas völlig Neues: "Neue Religionsgesellschaften dürfen sich bilden; einer Anerkennung ihres Bekenntnisses durch den Staat bedarf es nicht. « Dieser Dreiklang von Gewissens-, Kultus- und Vereinigungsfreiheit erwies sich als stilbildend für spätere Verfassungen wie diejenige Weimars oder der Bundesrepublik Deutschland. ${ }^{23}$ Gemäß I46 der Paulskirchenverfassung wird durch das religiöse Bekenntnis der Genuss der bürgerlichen und staatsbürgerlichen Rechte weder bedingt noch beschränkt. \$ I47 II zieht die Konsequenz für die staatsorganisatorische Seite, indem normiert wird: »Keine Religionsgemeinschaft genießt vor andern Vorrechte durch den Staat; es besteht fernerhin keine Staatskirche. «Entfallen ist mit alledem die korporative Einbindung der Religionsfreiheit, entfallen auch die staatliche Aufsicht über die Religionsgemeinschaften, entfallen schließlich das abgestufte System von exercitium publicum, exercitium privatum und Hausandacht, entfallen letzthin jede Identifikation des Staates mit einer bestimmten Glaubensrichtung.

\section{Preußische Verfassung von $\mathrm{I} 85^{\circ}$}

Nun wissen wir, dass die Paulskirchenverfassung an den restaurativen Gegenkräften scheiterte. Ihr Programm war insgesamt zu fortschrittlich und zu liberal, um die politische Wirklichkeit bereits umfassend gestalten zu können. Allerdings finden zentrale Elemente Eingang in die Preußische Verfassungsurkunde von I 850 , die in ihrem Art. I 2 insbesondere die Freiheit der Vereinigung zu Religionsgesellschaften gewährleistet sowie die bürgerliche und staatsbürgerliche Gleichheit auf alle Staatsangehörigen ohne Unterschied der Konfession erstreckt (»Die Freiheit des religiösen Bekenntnisses, der Vereinigung zu Religionsgemeinschaften ... und der gemeinsamen häuslichen und öffentlichen Religionsausübung wird gewährleistet. «). Das Christentum als Staatsreligion nach dem Vorbild der Charte Constitutionelle Française von I8I4 (Art. 6: »Indessen ist die römisch-katholische Religion die Religion des Staats. «) kennt die Preußische Verfassung nicht. Dennoch wird die christliche Imprägnierung des Staates nicht nur als Faktor hingenommen, sondern in gewissem Umfang normativ

23 J.-D. KüHNE, Die Reichsverfassung der Paulskirche (I985), 2. Aufl. Neuwied I998, 470. 
festgeschrieben. Neben der Privilegierung von Religionen mit Korporationsrechten (PrVerf I 850, Art. I3) hält man vor allem an einer sozusagen natürlichen Grundierung des Staats- und Gesellschaftslebens durch das Christentum fest: »Die christliche Religion wird bei denjenigen Einrichtungen des Staates, welche mit der Religionsübung im Zusammenhange stehen, unbeschadet der im Art. I2 gewährleisteten Religionsfreiheit zugrundegelegt. «(Art. I4). Letztlich standen hinter dieser nicht ganz leicht zu interpretierenden Norm wohl relativ konkrete Befürchtungen, die staatliche Anordnung und Durchführung der Sonntagsruhe, der christlichen Feiertage oder der christlichen Militärseelsorge sei ohne diesen Zusatz wegen der ansonsten gewährten Religionsfreiheit nicht mehr unangreifbar. ${ }^{24}$ Weitergehende Vorstellungen von Vertretern eines "christlichen Staates « wie Friedrich Julius Stahl vermochten sich allerdings ebensowenig durchzusetzen. So indiziert die Norm eine eigentümliche Schwebelage: einerseits relativ weitgehende individuelle Glaubens- und Kultusfreiheit, andererseits die besondere Hervorhebung der christlichen Religion als eines hervorgehobenen Moments des staatlichen Selbstverständnisses im Sinne einer ethischen Gleichordnung von Staat und Kirche. ${ }^{25}$ Diese Vorstellung wird erst mit der Weimarer Reichsverfassung und dem Grundgesetz überwunden.

7. Weimarer Reichsverfassung I9I9 und Grundgesetz I949

Die Weimarer Reichsverfassung (WRV) kann in vielerlei Hinsicht an das liberale Programm der Paulskirchenverfassung anknüpfen und übernimmt mehrere Regeln fast wörtlich (Art. I35: "Alle Bewohner des Reichs genießen volle Glaubens- und Gewissensfreiheit. Die ungestörte Religionsausübung wird durch die Verfassung gewährleistet und steht unter staatlichem Schutz." Art. I36: "Die bürgerlichen und die staatsbürgerlichen Rechte und Pflichten werden durch die Ausübung der Religionsfreiheit weder bedingt noch beschränkt. «). Darüber hinaus baut sie gewisse überkommene Verknüpfungen zwischen (christlichem) Glauben und staatlicher Rechtsordnung konsequent $\mathrm{ab}$ und komplettiert so den Selbstand der religiösen (oder areligiösen) Überzeugung. Eidesleistungen können nun - im Unterschied zur Paulskirche ${ }^{26}$ ohne den Zusatz "So wahr mir Gott helfe " erbracht werden (Art. I77 WRV); auch war der Religionsunterricht nicht mehr

24 Siehe die Erläuterungen bei G. ANschüTz, Die VerfassungsUrkunde für den Preußischen
Staat, Bd. I, Berlin I9I 2, $260 \mathrm{ff}$. (26I, 264, 266), der die Notwendigkeit eines besonderen Artikels aber bestreitet.

25 Signifikant Anschütz, Verfassungs-Urkunde (Fn. 24) 267: $\gg \mathrm{Al}$ les in allem kann man sagen, daß das auf dem Gedanken der ethischen Gleichordnung von Staat und christlicher Kirche beruhende, in der Begünstigung der Kirche und der Berücksichtigung des
Christentums im öffentlichen Leben sich bestätigende Schutzrecht des Staates, die Advokatie, so, wie sie auch ohne den Art. I4 ein zweifelloses Recht des Staates gewesen und geblieben wäre, durch den Artikel in gewissen Grenzen zu einer staatlichen Pflicht geworden ist."

26 Differenzierend zur dortigen Regelung KüHNE, Reichsverfassung (Fn. 23) $472 \mathrm{ff}$. 
obligatorisch und konnten die Lehrer durch jederzeit zulässige Erklärung die Erteilung religiösen Unterrichts ablehnen (Art. I49 II WRV). ${ }^{27}$ Schließlich wird die Freiheit der Vereinigung zu Religionsgesellschaften gewährleistet (Art. I37 II WRV). Das somit erreichte Niveau an religiöser Freiheit umschrieb Gerhard Anschütz seinerzeit wie folgt: »Religionsfreiheit ist die dem Individuum staatlich gewährleistete rechtliche Möglichkeit, sein Verhältnis zu allen religiösen Fragen nach Belieben gestalten, seinen religiösen, irreligiösen, antireligiösen Überzeugungen gemäß leben zu dürfen, alles tun zu dürfen, was diese Überzeugungen fordern, alles unterlassen zu dürfen, was sie verbieten, in allen Beziehungen frei zu sein von staatlichem Zwang, - aber unter dem Vorbehalt des Gehorsams gegen die allgemeinen Staatsgesetze. ${ }^{28}$

Das Grundgesetz für die Bundesrepublik Deutschland (GG) übernimmt von der Weimarer Reichsverfassung ${ }^{29}$ nicht allein mehrere überwiegend staatskirchenrechtliche, hier nicht weiter zu untersuchende Regelungen, die es - einschließlich des »Privilegienbündels « für die Religionsgesellschaften mit dem Status öffentlichrechtlicher Körperschaften - über Art. I40 GG inkorporiert. Vielmehr schließt sich auch Art. ${ }_{4}$ GG mit seinen verschiedenen Garantien an Frankfurter und Weimarer Vorbilder an. In der Sache wohl eher klarstellend, ${ }^{3 \circ}$ gleichwohl normtextlich deutlich hervorgehoben, tritt aber neben das tradierte religiöse Bekenntnis gleichberechtigt das weltanschauliche (Art. 4 I GG: »Die Freiheit des Glaubens, des Gewissens und die Freiheit des religiösen und weltanschaulichen Bekenntnisses sind unverletzlich.«). Weltanschauungen können bekanntlich auch dezidiert a- oder gar antireligiöse Philosophien oder sonstige Welterklärungsmodelle umfassen. ${ }^{3 \mathbf{I}}$ Als Grundrecht steht die Areligiosität - anders als zum Beispiel in der Paulskirche $3^{32}$ - somit der Religiosität verfassungsnormativ gleich. Jetzt wird »neben dem transzendenten Glauben auch die säkulare Weltanschauung geschützt «. ${ }^{33}$ Damit erweist sich der Schutzgehalt der Garantie des Art. 4 GG als außerordentlich breit. Umfasst ist praktisch alles und von allem auch das Gegenteil: die Bildung religiöser Gemeinschaften wie der Austritt aus ihnen oder der Übertritt zu anderen; das positive Bekenntnis zu einer Religion resp. Konfession ebenso wie auch das bewusste Nichtbekenntnis (»negative « Religionsfreiheit); das Bekenntnis nicht zu einer Religion, sondern zu einer Weltanschauung, deren Profil dezidiert antireligiös ausgeprägt sein kann; schließlich auch das völlige Absehen

27 Anschütz, Religionsfreiheit (Fn. 9) 685.

28 AnschüTZ, Religionsfreiheit (Fn. 9) 68I.

29 Zum Übernahmeprozess sowie zum Vergleich der Beratungen in Weimar und im Parlamentarischen Rat instruktiv F. WITTRECK, Bonn ist doch Weimar. Die Religionsfreiheit im Grundgesetz als Resultat von Konflikt und Kontroverse, in: Religionskonflikte im Verfas- sungsstaat, hg. von A. Reuter, H. G. KippenberG, Göttingen 2010, 66-92.

30 Dies, wenn man der Auffassung von Gerhard Anschütz folgt, demzufolge durch Art. I35 WRV "die religionslose (insb. atheistische) Weltanschauung « genau so freigegeben war »wie jede religiöse (theistische) «(G. ANSCHÜTZ, Die Verfassung des Deutschen Reichs vom I I. August I9 I9, I4. Aufl.
Berlin I933, Art. I35 Anm. 4 Fn. 2 [S. 6I9]). Bemerkenswerter-, wenngleich nicht überraschenderweise den Schutz des Art. I35 WRV von der »antireligiösen Überzeugung « ausnehmend C. Sснмітт, Inhalt und Bedeutung des zweiten Hauptteils der Reichsverfassung, in: ANSCHÜTz/THOMA, Handbuch (Fn. 9), \ IOI, 572-606 (584).

3 I Knapp angedeutet bei v. CAMPENHAUSEN, Religionsfreiheit (Fn. I2), \I 57 Rn. 59.

32 Siehe KüHnE, Reichsverfassung (Fn. 23) $472 \mathrm{f} ., 476 \mathrm{f}$.

33 Morlok (Fn. I 5), Art. 4 Rn. I I. 
von jeglicher - transzendenter oder materialistischer - Bindung an irgendein System der "Sinnorientierung ". ${ }^{34}$ In den Worten Klaus Schlaichs sieht der vorläufige Abschluss des Säkularisierungsprozesses im Bereich der Religionsfreiheit so aus: »Die Glaubensbzw. Religionsfreiheit ist heute gewährleistet in gleicher Weise für Gläubige, für Atheisten und für Gleichgültige. Die Religionsfreiheit privilegiert also nicht den Glauben; sie ist ein Recht in säkularem Gewand, das der Erfüllung im religiösen Geist ebenso offen steht wie dem Gegenteil. «35

III. Religionsfreiheit im säkularen Staat unter den Bedingungen gesteigerter Pluralisierung

Was lässt sich nun aus dieser Tour d'horizon durch die Geschichte der Religionsfreiheit in Deutschland für die Ausbildung eines säkularen Staates schlussfolgern?

Die Rekonstruktion der Entwicklung demonstriert zunächst, wie konfliktreich und langwierig die Ausbildung eines säkularen Staates war. Es zeigt sich aber auch, dass sukzessive Säkularisierungsschritte im Sinne eines Rückzuges des Staates aus dem Felde des Glaubens erfolgen können, ohne dass der individualistische Grundrechtsgedanke bereits seinen Siegeszug angetreten hat. Die Bestimmungen des Augsburger und stärker noch die des Westfälischen Vertrages demonstrieren dies deutlich. Hier geht die sukzessive Ausbildung korporativ gebundener Religionspluralität der vollständigen Individualisierung der Religionsfrage weit voraus. Diese Pluralität (erst Glaubenszweiheit, dann Glaubensdreiheit) gewährt gleichsam reflexweise mit der Auswanderungsfreiheit ein frühes Individualrecht und kann sich dann I648 bis zur Duldung von Minderheitenbekenntnissen, also der Toleranz im eigentlichen Sinne, steigern, wie die Regelungen zur Hausandacht belegen. Die Restriktion auf die Hausandacht indiziert dabei, wie wichtig die Religion als Staatsreligion und damit als Form kollektiver Identität weiterhin bleibt. Lange Zeit galt eben unumstößlich der Satz: »Un roi, une loi, une foi «. Erst wenn der Staat die Glaubensfrage als Wahrheitsfrage privatisiert hat und sich mit keiner Religion und keiner Konfession mehr identifiziert, kann volle Religionsfreiheit und schließlich sogar Weltanschauungsfreiheit gewährt und rein individualrechtlich konzipiert werden.

34 Morlok (Fn. I 5), Art. 4 Rn. 42.

35 K. Schlaich, Konfessionalität Säkularität - Offenheit. Der christliche Glaube und der freiheitlichdemokratische Verfassungsstaat (1985), in: DERS., Gesammelte Aufsätze. Kirche und Staat von der Reformation bis zum Grundgesetz, hg. von M. HeCKel, W. Heun, Tübingen I997, 423447 (430f.). 
»Die Entwicklung geht von der Konfessionalität über die Parität bzw. konfessionelle Pluralität zur Neutralität bzw. Säkularität des Staates. ${ }^{36}$ Das schließt die Abschaffung einer Staatskirche notwendigerweise ein.

Umgekehrt kann man fragen, ob eine völlige Säkularisierung des politischen Gemeinwesens der Bundesrepublik Deutschland und ihrer Rechtsordnung überhaupt möglich ist. Gibt es einen logischen Endpunkt des Säkularisierungsprozesses? Und selbst, wenn man das bejahen müsste: Wäre es geboten, diesen Endpunkt anzustreben? Diese Frage betrifft in erster Linie die sozusagen kulturelle Dimension unseres Problems. Denn wenn richtig ist, dass das Christentum in Europa viele Jahrhunderte lang ein maßgeblich prägender Kulturfaktor war, dann können sich entsprechende Prägungen von Gesellschaft und Staat nicht einfach in Luft auflösen. ${ }^{37}$ Sofern sich allerdings diese Prägungen auf die Gestaltung der für alle gleichermaßen verbindlichen Rechtsordnung auswirken, stellen sich zuweilen schwierige Fragen.

Lehrreich ist hier ein mittlerweile schon wieder rechtsgeschichtlicher Vorgang aus den I 96oer Jahren. Seinerzeit existierten noch Straftatbestände wie die Homosexualität (unter erwachsenen Männern), die Kuppelei oder der Ehebruch. Zur Begründung für diese Straftatbestände wurde zumeist auf das Sittengesetz verwiesen, hinter dem sich aber evidentermaßen bestimmte christliche Glaubenssätze und entsprechende Werthaltungen verbargen. Die Streichung der einschlägigen Strafnormen Ende der I96oer Jahre erfolgte mit ausdrücklichem Hinweis darauf, dass das Strafrecht nur Rechtsgüter der Allgemeinheit und des Einzelnen schützen könne und dürfe, nicht aber bestimmte moralische oder religiöse Anschauungen. Die religiöse Neutralisierung positiven Rechts wird ferner daran sichtbar, dass der frühere Straftatbestand der Gotteslästerung entfallen und heute nicht nur die Beschimpfung des religiösen, sondern auch des weltanschaulichen Bekenntnisses untersagt ist. ${ }^{38}$ Es geht nicht um eine »Beleidigung " Gottes. Als Schutzgut des $\mathbb{S}$ I 66 StGB firmiert daher auch nicht die Religion, sondern der öffentliche Friede. ${ }^{39}$ In solchen und vergleichbaren Vorgängen lassen sich durch den Säkularisierungsprozess unausweichlich gewordene Absetzbewegungen vom materiell christlichen Erbe im Bereich des einfachen positiven Rechts ausmachen. Der entsprechende Rechtfertigungsdruck dürfte zukünftig noch die eine oder andere Regelung in Bedrängnis bringen, wobei wohl
36 SChlaich, Konfessionalität (Fn. 35 ) 438. Schlaich argumentiert im Übrigen auch deutlich gegen weiterlebende Vorstellungen einer »ethischen Gleichordnung « von Staat und Kirche (ebd., 44 I ff.).

37 Das Problemfeld ist etwas systematischer und eingehender als hier entfaltet bei H. DreIER, Religion und Verfassungsstaat im Kampf der Kulturen, in: Kulturelle Iden- tität als Grund und Grenze des Rechts, hg. von H. Dreier, E. Hilgendorf, Stuttgart 2008, II-28 (I6 ff., 2I ff.).

38 Eingehend dazu und zugleich sehr kritisch zu den gängigen Erklärungsmustern M. PAwlik, Der strafrechtliche Schutz des Heiligen, in: Religionsbeschimpfung. Der rechtliche Schutz des Heiligen, hg. von J. Isensee, Berlin 2007 , 3I-6I.
39 Kritisch dazu T. Hörnle, Strafrechtliche Verbotsnormen zum Schutz von kulturellen Identitäten, in: Dreier / Hilgendorf (Fn. 37) 3I 5-337 (326f.). 
40 Zur Deutung dieser Aussage als »Demutsformel« H. DreIER, in: ders. (Hrsg.), Grundgesetz-Kommentar, hg. von H. DREIER (Fn. I 5), Bd. I, Präambel Rn. 28. mancher tradierte Normenbestand im säkularen Gewand oder durch interpretatorische Verwandlung von genuin christlichen Gehalten in vorgeblich religionsneutrale Bildungs- oder Kulturfaktoren wird überleben können.

Von besonderer Bedeutung ist die Frage, wie weit sich die Verfassung eines säkularen Staates explizit auf religiöse (nicht zwingend christliche) Aussagen oder Gehalte beziehen oder sich auf sie stützen darf. So spricht das bundesdeutsche Grundgesetz in seiner Präambel unverändert davon, es sei »in Verantwortung vor Gott « beschlossen worden. ${ }^{4 \circ}$ Einige Länderverfassungen normieren die »Ehrfurcht vor Gott « als Erziehungsziel. Die Eidesformeln, die etwa der Bundespräsident und andere Inhaber hoher Staatsämter bei ihrem Amtsantritt zu sprechen haben, weisen (ob mit oder ohne religiöse Beteuerung) allein durch die Formulierung des »ich schwöre" einen starken metaphysischen Bezug auf. Eine gewisse Identifikation des Staates mit bestimmten religiösen Zeichen und Aussagen liegt auch vor, wenn in öffentlichen Räumen von Schulen oder Gerichten Kreuze oder Kruzifixe angebracht sind. Mit dem Stichwort der Kruzifix-Entscheidung(en) ist ein weites und hier nicht annähernd abzuschreitendes Problemfeld bezeichnet. Bezeichnend für die hochkontroverse Lage sind die hierzu ergangenen unterschiedlichen Urteile etwa des Bundesverfassungsgerichts ${ }^{4 \mathrm{I}}$ und - vor kurzem - des Europäischen Gerichtshofs für Menschenrechte, ${ }^{42}$ von der kontroversen Debattenlage im Bereich der Rechtswissenschaft mit ihrer abundanten Literaturproduktion gar nicht zu reden.

Mit den (öffentlichen) Schulen ist ohnehin das in jüngerer Zeit bevorzugte Konfliktfeld für Auseinandersetzungen um Grenzen der Religionsfreiheit oder auch der Säkularität des Staates benannt. Hier muss man aber zum einen betonen, dass sie das eigentlich schon immer waren - erinnert sei an die einschlägigen Bestimmungen in der Weimarer Reichsverfassung. Man hat das Problem seinerzeit wie auch später lediglich durch forcierte Konfessionalisierung der Schulen gelöst bzw. eher ruhiggestellt. Mittlerweile ist allerdings durch die Entwicklung der Bundesrepublik Deutschland von einem bikonfessionellen zu einem multireligiösen Staatswesen eine qualitative und quantitative Verschärfung des Konfliktfeldes eingetreten. Zum anderen kann nicht genug betont werden, dass gerade der säkulare Staat, der Religionsfreiheit gewährleistet, sich mit dem öffentlichen Bekenntnis privaten und persönlichen Glau-
42 EGMR, Urt. v. I 8.3.20I I, Lautsi u. a. ./. Italien, Az.: 308 I $4 / 06$. Dieser Entscheidung der Großen Kammer zufolge verstößt es nicht gegen Art. 2 Prot. Nr. I und Art. 9 EMRK, dass in Italien Kruzifixe in Klassenzimmern staatlicher Schu- len hängen. Dagegen hatte das vorangegangene Kammerurteil (v. 3.I I.2009) zunächst den Be- schwerdeführern Recht gegeben.


bens, also mit sichtbarer Religionsausübung, konfrontiert sieht. Privatisierung der Religion bedeutet eben gerade nicht die für die Öffentlichkeit unsichtbare Hausandacht nach dem Muster des Westfälischen Friedens, sondern meint, dass der Staat als Hoheitsgewalt sich neutral gegenüber den Religionen verhält. Im freiheitlichen Verfassungsstaat darf, ja soll die Religionsausübung privater Personen und ihrer Organisationen in der Öffentlichkeit sichtbar werden. Insofern verwirrt auch etwas die namentlich in soziologischen Stellungnahmen zur Säkularisierungsproblematik dominante Redeweise von der Privatisierung der Religion (bzw. von ihrer Rückkehr in die Öffentlichkeit), weil sie die Öffentlichkeit als gewissermaßen natürliche Sphäre der Grundrechtsausübung verkennt. ${ }^{43}$ Zudem kann gerade strenge religiöse und weltanschauliche Neutralität des Staates die Kraft und innere Bedeutung des religiösen Bekenntnisses und seiner Ausübung ganz erheblich stärken, wenn sie mit effektiven grundrechtlichen Freiheitsgarantien einhergeht. ${ }^{44}$ Diese gelten freilich nicht allein für Religionen und schon gar nicht für nur eine Religion. Die Wahrnehmung der Religions- und Weltanschauungsfreiheit führt daher gerade wegen ihrer grundgesetzlich garantierten öffentlichen Ausübung durch die Grundrechtsträger dazu, dass es - wie bei anderen Grundrechten auch - zu Spannungen und Konflikten kommen kann: sei es mit anderen Grundrechten wie der Meinungs- oder Kunstfreiheit, sei es zwischen den religiösen Grundrechtsträgern, sei es im Verhältnis zu staatlichen Beschränkungen oder Inpflichtnahmen. Hier muss, wie bei anderen Grundrechten auch, der Grenzverlauf zwischen grundrechtlich garantierter Freiheit und ihren legitimen Beschränkungsmöglichkeiten beständig neu geprüft und gegebenenfalls korrigiert werden. Die allseits bekannten Fälle, die gerade in Deutschland in den letzten Jahren Aufmerksamkeit erregt haben (Kopftuch der Lehrerin, Befreiung muslimischer Mädchen vom Sportunterricht, Mohammed-Karikaturen, Schächten von Tieren aus religiösen Gründen etc.), zeigen, wie schwierig das Ziehen einer allseits konsentierten Linie ist. Dabei sollte allerdings - deutlicher, als dies häufig geschieht - zwischen der Ausübung der Religionsfreiheit bei Innehabung eines staatlichen Amtes, das zur Mäßigung verpflichtet (Kopftuch der beamteten Lehrerin), und Freiheitsausübungen durch Privatpersonen unterschieden werden. Was die Freiheitsausübung verschiedener Individuen oder Gruppen betrifft, so wird sie gerade angesichts geschlossener kultureller Milieus mit

43 Schon zu Art. I35 WRV wurde kommentierend bemerkt: "Alle Kultusprivilegien einzelner Kirchen und Konfessionen sind beseitigt, jeder Kultus darf sowohl häuslich als öffentlich und mit den altherkömmlichen Zeichen der Öffentlichkeit (insbesondere Ausstattung der Kirchengebäude mit Turm und Glocken ...) ausgeübt werden.«So ANschüTz, Verfas- sung (Fn. 30), Art. I35 Anm. 5 (620f.).

44 Statt vieler Schlaich, Konfessionalität (Fn. 35 ) 444 . 
geringer Toleranzfähigkeit und ausgeprägtem Kränkungsfetischismus von der jeweils anderen Seite häufig als unerträgliche Zumutung empfunden. Der freiheitliche, plurale Staat des Grundgesetzes lebt aber davon, dass (und er wird nur fortleben, solange) solche Zumutungen in weitem Umfang ertragen werden. Speziell für die Religionsfreiheit gilt hier, was Michael Stolleis schon im Jahre 1972 festgestellt hat: "Die Konfrontation mit der Religionsausübung anderer kann in einem pluralistischen Gemeinwesen niemand mit Hilfe des (de jure) weltanschaulich neutralen Staates von sich fernhalten. $« 45$

Horst Dreier

45 M. Stolleis, Kirchliches Glo-

ckenläuten und staatliche Gerich-

te, in: ZevKR I7 (I972) I 50-I 56

(I54). 